\title{
Time waits for no man
}

\section{Do you know what you think before you see what you say?}

\section{Mind Time: The Temporal Factor in Consciousness \\ by Benjamin Libet \\ Harvard University Press: 2004. 288 pp. \\ \$29.95, £19.95, €27.70 \\ Kevan Martin}

"I did not know I loved you till I heard myself telling you so - for one instant I thought, 'Good God, what have I said?' and then I knew it was the truth." Bertrand Russell's report of his late-night conversation with Ottoline Morrell captures the essential thesis of Benjamin Libet's monograph on the temporal factor in consciousness. Libet reviews his extended set of experiments, which he believes show that Russell was right: reality is running about half-a-second ahead of our conscious awareness of it. The bad news is that we never catch up.

Studies of awareness and consciousness by neurobiologists and psychologists are now mainstream, and even young scientists can expect to pursue a well-funded career in consciousness studies. It was not always so. As Francis Crick records in his own book on consciousness, The Astonishing Hypothesis (Simon \& Schuster, 1994), Libet only dared switch to the study of consciousness after he got tenure. It is fortunate for us that he did, and that he has presented us here with what amounts to a retrospective exhibition of his work. The book is something of an atavism, resembling more an early work of his mentor Jack Eccles than the glossy volumes that now appear in the field. But the refreshing result is that we are immediately engaged in an earnest one-to-one tutorial with Libet.

Libet was fortunate to link up with the neurosurgeon Bertram Feinstein, who gave him the chance to study the neocortex of conscious patients who were undergoing brain surgery under local anaesthesia. Libet took advantage of the discovery by Wilder Penfield and Herbert Jasper that conscious sensations of touch, referred to a particular place on the skin, can be evoked by electrically stimulating the surface of the somatosensory cortex.

Libet's initial discovery was that the train of stimulation pulses had to last for 200-500 milliseconds before the sensation of touch was perceived consciously. This delay - the 'mind time' - led him to propose his 'timeon theory', which states that conscious sensory experience requires that the appropriate brain activities turn on for at least $500 \mathrm{~ms}$, and that shorter brain activities may lead to an unconscious mental function. This latter hypothesis is needed to explain fast reaction times, such as those of champion 100-metre sprinters who leave their blocks a mere $130 \mathrm{~ms}$

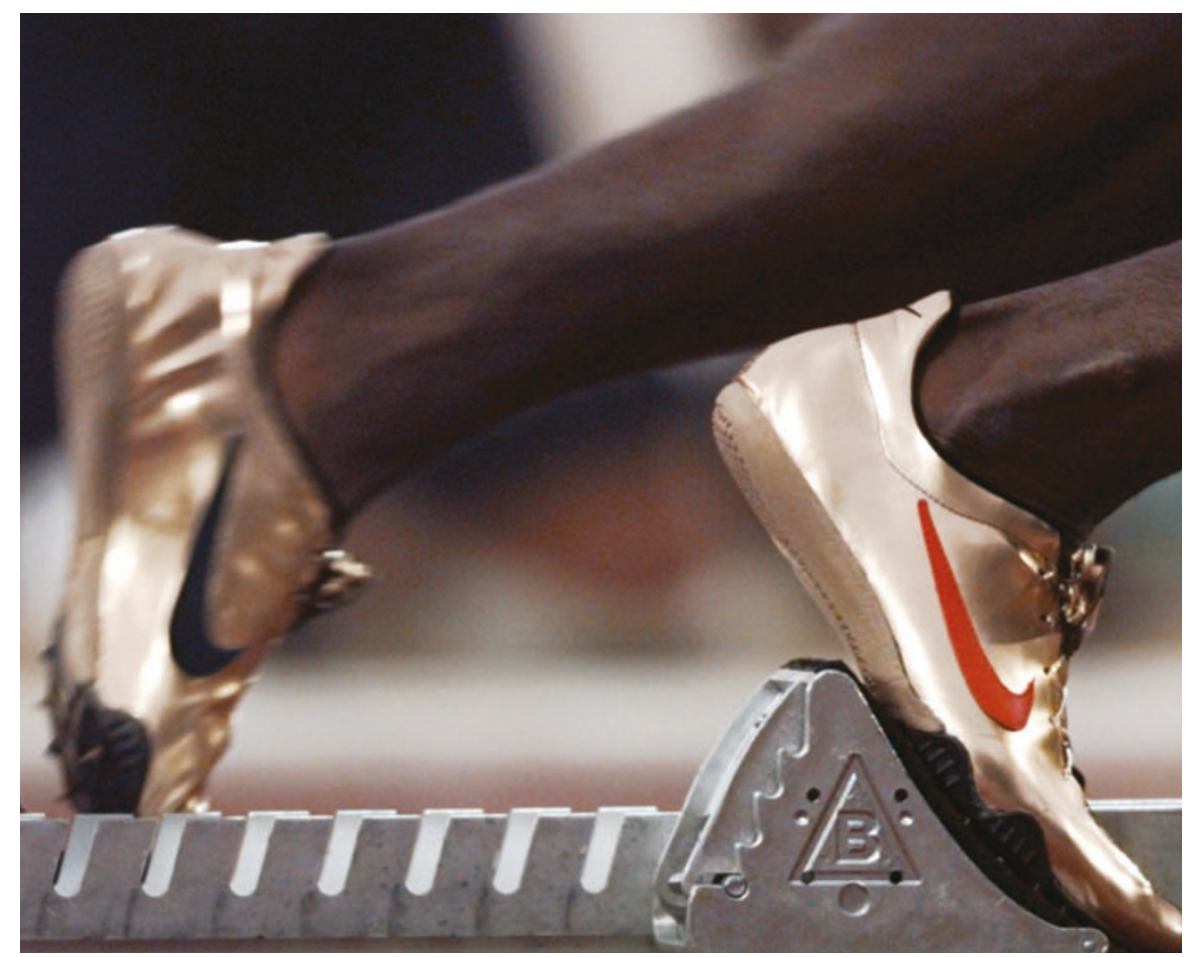

Quick off the mark: Michael Johnson can be up and running before he is aware that the gun has fired.

after the starting pistol fires, suggesting that they are only aware that the gun has fired after they have left their blocks. But can the brain states of a patient undergoing brain surgery really be extrapolated to an athlete poised to break a world record?

In the visual system, electrical stimulation of the cortex in humans does not produce much more than tiny spots of light called phosphenes, as Giles Brindley discovered in the early 1960s. Bill Newsome and his colleagues found that direct electrical stimulation of the visual area called MT in monkeys influences the motion perception of the monkey only if it is combined with a real visual stimulus. The direct electrical stimulation on its own does not evoke a perception, or at least one that the monkey can report, so it has been difficult to use animal models to explore such issues.

Single impulses evoked in a sensory nerve by touching the skin can be detected, so one criticism of Libet's result is that when he stimulates the brain it evokes a rather coarse spatiotemporal pattern of cortical activation. The brain may simply be doing its best to make sense, literally, of the artificially induced activity of neurons that are normally activated from a patch of skin. This may take longer than usual, as the neural programs need to do the interpreting.

Libet's most controversial claim is that, because subjectively we believe that we are immediately aware of the stimulus, there must be a disjunction between subjective timing and neuronal timing. On the basis of various experiments, he suggests that our sense of immediacy is an illusion that arises because we refer the timing of the experience back to the time of the earliest cortical activity, evoked some 10-30 ms after the skin is touched. The neural mechanisms by which all this precise time calculation has to be carried out is, of course, unknown.

Those of us for whom a slip of the tongue is a regrettably familiar event might be comforted to read here that, as in the case of sensory events, our conscious intention to act lags 300-500 ms behind the relevant brain events that actually lead to action. This of course raises the thorny question of who is actually doing the intending, as our conscious selves seem to be lounging in the back seat being chauffeured around by our zombie doppelgänger. The best we can do, it seems, is occasionally lunge for the steering wheel when our limousine takes a wrong turn. This is perhaps not quite as strange as it sounds, because highly practised movements, such as those of skilled musicians, are produced at rates that seem faster than thought.

In Libet's work, philosophers have found grist for what they do best. Indeed, his experiments, along with Larry Weiskrantz's discovery of blindsight, must rank as one 
of the major contributions of experimental psychology to modern philosophy of mind. Humans and monkeys with extensive damage to their primary visual cortex are clinically blind, but Weiskrantz found that they were surprisingly accurate about identifying the position and shape of objects when he forced them to guess. Philosophers, however, have not always been as appreciative of Libet's gift as they have of Weiskrantz's. Paul Churchland, Ted Honderich and Daniel Dennett, in particular, have attacked Libet's methods, results and ideas (and, in fairness, also each others'). What so vexes them is Libet's relegation of consciousness to the role of observer and occasional vetoer of action, which compromises both the cartesian view, in which the mind controls the machinery of the body, and the materialist view, where mind and brain events are identical.

Libet has replies for his critics, of course, but in developing his alternative theory, he ends up putting the ghost back in the machine in the form of a 'conscious mental field' emanating from the brain. This may be going too far, but whether or not one agrees with his thesis or not, one must acknowledge that his pioneering experimental work has certainly been stimulating.

Kevan Martin is at the Institute of

Neuroinformatics, ETH/University of Zurich,

Winterthurerstrasse 190, Zurich 8057, Switzerland.

$\cdots \cdots \cdots \cdots$

\section{A global problem}

\section{Global Change and the Earth}

System: A Planet under Pressure

by W. Steffen, A. Sanderson, P. D. Tyson,

J. Jäger, P. A. Matson, B. Moore III, F. Oldfield,

K. Richardson, H. J. Schellnhuber,

B. L. Turner II, R. J. Wasson

Springer: 2004. 336 pp. \$129, £77, €99.95

\section{Hans von Storch}

This book "focuses on the profound transformations of Earth's environment that is now apparent, a transformation owing not to the great forces of nature or to extraterrestrial sources, but to the number and activities of people - the phenomenon of global change".

The authors have adopted a systematic approach. They begin by describing the Earth system - the whole of the physical and ecological environment that determines the state of the Earth - which they view as one integrated system. Next they discuss the dynamics of the Earth system as it was before human influence: the characteristics of temporal and spatial variability, the role of biological processes, the connectivity between the different parts of the system, and the role of nonlinearities, such as the browning of the Sahara. The third chapter describes the

\section{A world of paint}

Visual art has one of the

longest and fullest records of

any human activity. Humans

have been recording images

of the world around them for

more than 30,000 years. In

Atlas of World Art (Laurence

King, £75), art historian John

Onians has coordinated

the work of a group

of anthropologists,

archaeologists and

art historians to

compile a temporal

and geographic

history of art.

Pictures of art, like

the African masquerade

shown here, take second

place to detailed maps

showing the cultural

influences and location of

key sites and artistic centres

on each continent in seven

different periods, from

$40,000-5,000 \mathrm{BC}$ to the

twentieth century.

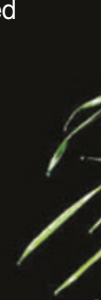

4

L.

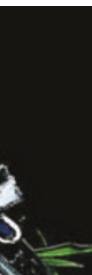

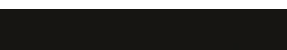

(1)
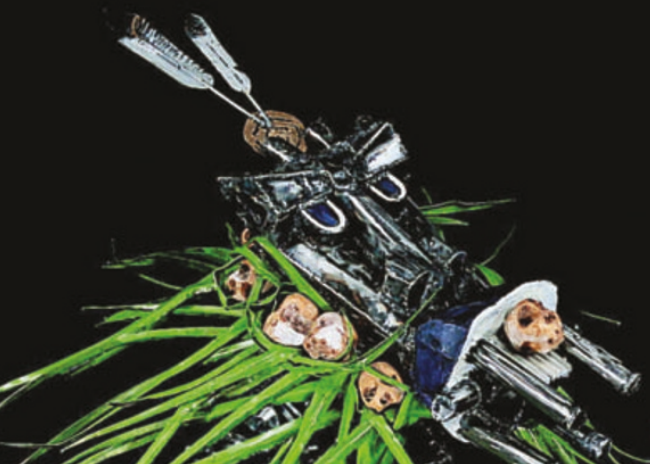

西
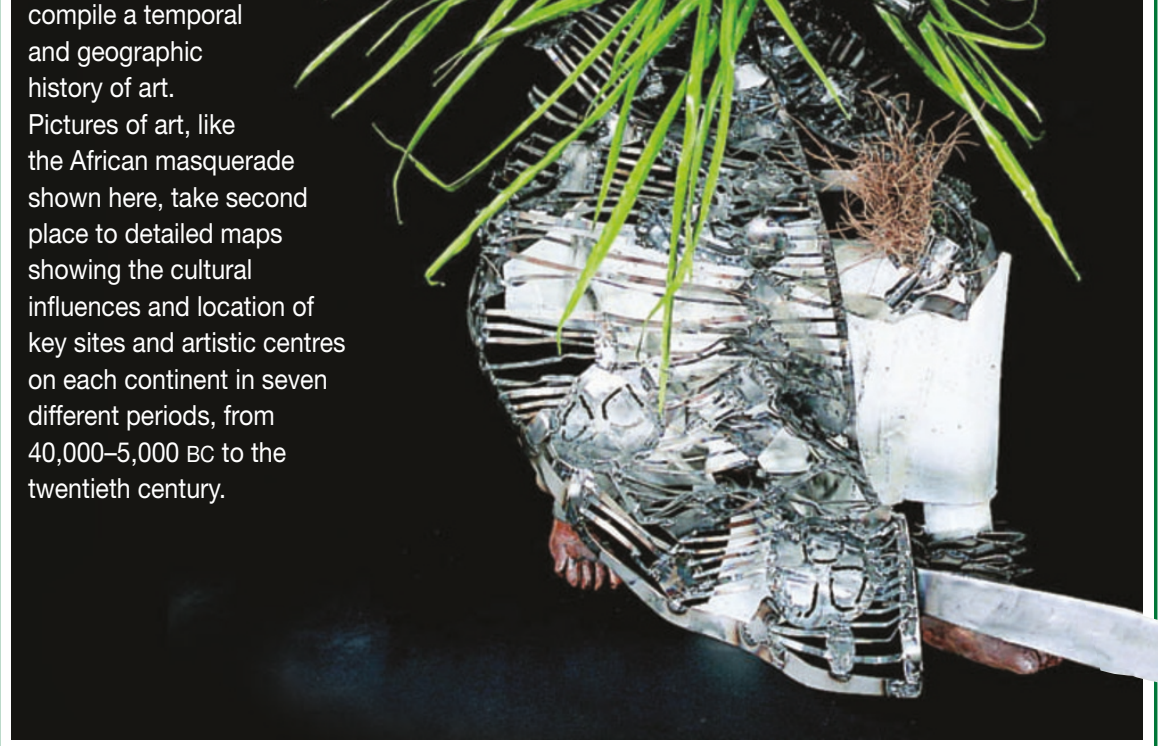

Anthropocene, the most recent part of Earth history, which has been, and continues to be, massively influenced by humans. Here the authors identify the drivers of change, characterize these changes, and put them into perspective in relation to the overall change of the Earth system. The fourth chapter then deals with the responses of the Earth system to human activities. The authors cover the entire spectrum of anthropogenic change, from emissions, changes in land use and land cover, and fires in South-east Asia, to the effect on coral reefs and the overall response of the Earth system with respect to climate and the water cycle, for example. They then examine the consequences of these changes for human well-being. The key points here relate to anticipation of future change, risks to key resources, and dangers to the Earth system as a whole. There is also a rather brief discussion of human perceptions of global change. In the final chapter, the authors draw various conclusions about the contemporary knowledge base, Earthsystem science and the need for a toolkit with which to pursue the overarching goal of global sustainability.

The book is part of a series published for the International Geosphere-Biosphere
Programme(IGBP), one of four international global environmental-change research programmes sponsored by the International Council for Science. The IGBP's objectives are "to describe and understand the interactive physical, chemical and biological processes that regulate the total Earth System, the unique environment that it provides for life, the changes that are occurring in this system, and the manner in which they are influenced by human actions".

Global Change and the Earth System is richly illustrated with many useful coloured diagrams, and numerous boxes by additional authors provide more detailed information about specific issues. However, the wealth of detail makes it hard to read, and at times the diagrams are not properly explained.

Is it a good book? I am not entirely convinced. It deals with a broader set of topics (including the number of McDonalds restaurants around the world, and the emission of heavy metals) than the Intergovernmental Panel on Climate Change (IPCC) Assessment Reports. But the IPCC reports are written by a broader community of scientists, with more diverse expertise, greater emphasis on the certainty as well as the uncertainty of knowledge, and with more convincing 